2019-12-01

\title{
A safer future with clues from earthquakes past
}

Menegon, L

http://hdl.handle.net/10026.1/18682

10.21820/23987073.2019.9.6

Impact

Science Impact, Ltd.

All content in PEARL is protected by copyright law. Author manuscripts are made available in accordance with publisher policies. Please cite only the published version using the details provided on the item record or document. In the absence of an open licence (e.g. Creative Commons), permissions for further reuse of content should be sought from the publisher or author. 


\section{Impact Objectives}

- Undertake detailed field observation and mapping of pseudotachylytes

- Estimate the creep rates and the viscosity of mylonites to confirm them as geological signatures of transient post-seismic deformation in the lower crust

- Conduct rock deformation experiments in the laboratory to reproduce shear zones observed in the field

\section{A safer future with clues from earthquakes past}

Dr Luca Menegon and Professor Iain Stewart are investigating fault lines in northern Norway to determine how evidence of past seismic shifts can teach us more about how the deep crust behaves during tectonic plate movement

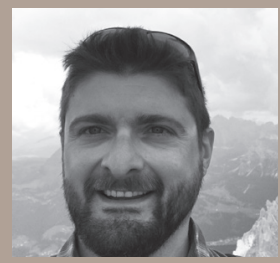

Dr Luca Menegon

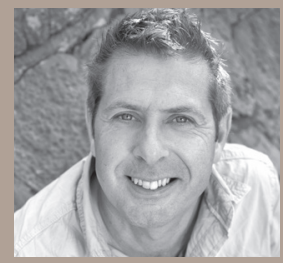

Professor Iain Stewart

Can you give us an overview of your project?

LM: This project focuses on an outstanding natural laboratory within a zone of ancient fault roots exhumed from lower crustal depth and now dramatically exposed in Nusfjord (Lofoten, northern Norway). The shear zone at Nusfjord exposes two different types of fault rock along the deep crustal fault roots. Pseudotachylytes are quenched frictional melt produced during seismic slip and are considered the only unequivocal evidence of past seismicity in the geological rock record (they are scars of past earthquakes). Mylonites are the product of the slow, steady, long-lasting viscous creep. Documenting the changing fault rock character and architecture showcases the switch in deformation process occurring in the lower crust between the rapid earthquake-related deformation and the slow creep that accommodates the long-term movement of the tectonic plates.

Why is it vital to understand both the longand short-term mechanical behaviour of the lower crust?
LM: In the context of the build-up and release of tectonic stress and strain (the earthquake cycle), our results will shed light on the earthquake source parameters in the lower crust and on the transient rheology that occurs after earthquake slip (post-seismic creep) in the lower crust. By characterising long-term rheology, our results will shed light on the strength evolution of the lower crust over multiple earthquake cycles, with co-seismic slip and associated fractures alternating with microstructural deformation related to viscous creep in the post-seismic period and the longer inter-seismic periods between earthquakes. This will improve our understanding of lower crust deformation during major geodynamic processes such as mountain-building processes and continental break-up during rifting and the associated expected seismicity or lack thereof.

What impact do you expect to have on the world at large?

LM: Most people see earthquakes as natural disasters that occur at plate boundaries, along seismic fault lines such as the San Andreas Fault in California. In fact, the planet's continents are criss-crossed by ancient fault scars because earthquakes are a fundamental part of how our planet accommodates the large-scale movement of Earth's outer skin. The geological study of faults is a critical part of modern Earth science.
IS: Our results will help us understand the controls on where earthquakes may nucleate and propagate in the lower crust and will inform earthquake hazard models with direct observations of the architecture and the mechanical properties of a deep earthquake source. Direct comparison between active tectonics and the geological record will help explain observations of deformation acquired before and after large earthquakes.

Please tell us about the documentary planned.

\section{IS: As geologists, we go to the extremes of} the planet, climb a mountain, carefully collect rock samples to take back to the laboratory where we examine them under powerful microscopes or crush them in high-pressure machines. All to get some numbers that try to define how the planet's internal processes work. It's all a bit abstract. The documentary is an outsider's view of how geologists work, almost like an anthropological perspective on this strange scientific tribe. A tribe that has its reference frame in the physical reality of the field, alongside the experimental and laboratory world of other sciences. One whose timeframes switch back and forth from the hundreds of millions of years of mountain building to the tens of seconds of earthquake slip. A group whose spatial scales of inquiry span the microscopic to the continental. In that sense, the documentary is about demystifying the nature of being a geologist as much as demystifying the nature of earthquake faults. 


\section{A window to the depths of the Earth}

Earthquakes can be devastating events but with further study of past seismic activity, we may better prepare for them in the future. Researchers at the University of Plymouth have undertaken an indepth investigation into the fossil record of earthquakes past

Amazingly, rock hundreds of millions of years old can tell us about the behaviours of our modern-day planet. Our planet is filled with traces of its past, like scars on its body and geologists can read these to uncover Earth's physical history. Deciphering this history can provide us with clues about how natural processes operate today and how they might continue to operate in the future. Earthquakes, some of the most jarring and active shapers of Earth's physical history, have the potential to destroy entire communities.

Dr Luca Menegon, Professor lain Stewart and their colleagues at the University of Plymouth are working around these limitations by studying fossil traces of earthquakes at a unique site in northern Norway. Menegon, the project's Principal Investigator, is Associate Professor of Structural Geology and Tectonics. Stewart, his research partner, is Professor of Geoscience Communication and Director of the Sustainable Earth Institute. He has also had a 15-year partnership with BBC Science, generating mainstream television documentaries about the planet.

Their exceptional field site in northern

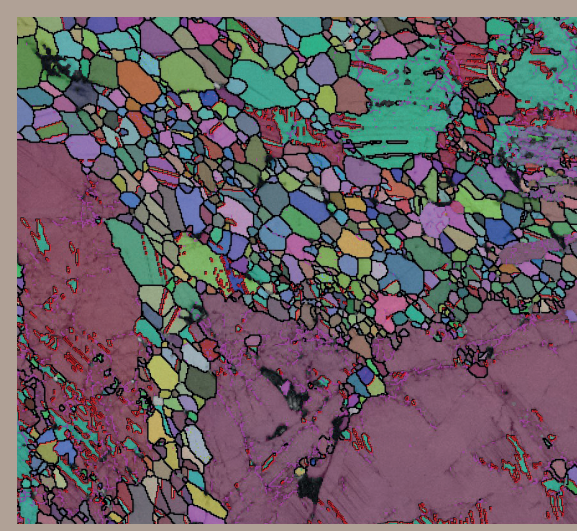

Electron backscatter diffraction map of the microstructure of a mylonite from the study area. Field of view is $0.5 \mathrm{~mm}$
Norway is currently tectonically inactive and seismically quiet. However, 400 million years ago, its rocky terrain formed the bottom of a Himalayan-scale mountain range plagued with earthquakes. The fossil traces of these earthquakes, exposed due to hundreds of millions of years of erosion, can now be evaluated by Menegon and his team to assess the history of seismic events and thus, predict future incidents.

\section{DIGGING DEEP}

The lower crust of our Earth, the layer between the outer crust and mantle, typically tens of kilometres deep beneath the surface, is a critical point of interest for geologists studying tectonics. It is down there where we find some of the largest earthquakes and their corresponding devastating aftershocks, such as the earthquake of 26 January 2001 in India that killed up to 20,000 individuals. In fact, these 'intercontinental earthquakes' have, over the past century, killed significantly more people than earthquakes striking at plate boundaries.

Improved understanding of these distressing and life-shattering earthquakes requires deeper study into the rheology, or the physics of flowing matter, of the lower crust and its relationship to surrounding earth as part of intracontinental earthquake cycles. Menegon and Stewart's research plans to elucidate this area of geology by establishing lower crust earthquake source parameters, rheology associated with postseismic creep and the evolution of the lower crust over the course of multiple earthquake cycles. Their work will thus improve understanding of major geodynamic processes in the lower crust, including mountain building and continental break-up during rifting as well as any seismicity associated with these processes.

\section{AN IDEAL SETTING}

The lower crust is not accessible to direct geological observation, and so its analysis must be instead constrained by geodynamic numerical models, laboratory experiments and large-scale geophysical surveys. However, it is possible, yet rare, to find occurrences of exhumed lower crustal earthquake sources providing the possibility of direct observation of fossil lower crustal processes. One of these exceptionally rare sites is in Lofoten, Norway, the team's designated site of exploration. There lies exposed ancient, lower crustal rocks that once hosted earthquakes, emerging from an opening in the Atlantic Ocean. 'This outstanding natural laboratory makes this project unique and further demonstrates the importance of direct field observations of geological structures to understand the dynamics of the Earth's crust and the mechanics of earthquakes,' explains Menegon.

It is not only the visible fossil earthquakes from the lower crust that make this site unique. During tectonic deformation, the lower crust is presumed to flow viscously, so the diagnostic scars of earthquakes in the geological record may be difficult to locate. The preservation of these particular scars is exceptionally rare, yet have been discovered in Lofoten.

\section{CLEAR INTENTIONS}

In analysing the Norwegian field site, the team has outlined well-defined objectives to document past earthquake activity and the subsequent viscous creep or slow movement recorded in fault rocks that formed in the deep crust and are now exposed at the earth's surface. 


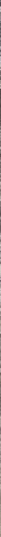

The earthquake cycle is a fundamental geological process and one that has huge significance for society

Firstly, they plan to undertake detailed field observation and mapping of pseudotachylytes, or pieces of the geological record indicating seismic slip or scars of earthquakes past, to determine earthquakesource parameters. This includes magnitude and stress drop and the differences between the stress across a fault before and after rupture by earthquake. Secondly, they will estimate the creep rates and the viscosity of mylonites, geological indicators of viscous creep, to confirm their role as geological signatures of temporary postseismic deformation in the lower crust. They also plan to compare creep rates and viscosity of mylonites with movement rates derived from geodetic studies of faults that are currently active, bridging the gap between their field-based geological studies and indirect seismological and geodetic observations. Thirdly, the team will determine effects of various amounts of aqueous fluid on mechanical behaviour and deformation processes in the lower crust, and lastly, they shall reproduce rock deformation experiments in the laboratory based on shear zones observed in the field.

\section{A PROMISING ROAD AHEAD}

Thus far, the team has gathered data matching their hypotheses. Specifically, their estimates of viscosity and deformation rates of mylonites from Lofoten are consistent with geodetic measurements of postseismic deformation in the deep roots of faults during current earthquake cycles, Campbell \& Menegon, 2019'.

The success of their work is partly due to their experienced team of geological specialists gathered from all over the UK and Europe. Spending weeks at a time together in the field studying earthquake sources and developing strategies for the follow-up laboratory work, they identify new avenues of research that could not have been created alone. 'Working as a multi-disciplinary team is at the core of this project. The research team consists of scientists with complementary skills and expertise that are ideally combined to shed light on the fundamental processes governing deep earthquakes and to effectively communicate our findings to the wide public,' explains Menegon.

The team's findings have been presented at international conferences and these are in the process of publication. The project will also reach a wider audience through partnerships with media professionals to generate accessible content for viewers, expanding public knowledge on the true nature of faults. 'Together with a documentary planned, this is still a work in progress,' adds Stewart. Stewart, having experience with television programmes in the past, has also developed a short film on YouTube entitled, 'Anatomy of an Earthquake'. With over 60,000 views, it is the Natural Environment Research Council's most watched science film.

'The earthquake cycle is a fundamental geological process and one that has huge significance for society,' states Stewart. Because earthquakes can have such disastrous effects on human society, it is not only imperative that the team study the intricacies of seismogenic fault behaviour to improve hazard assessments, but also that they educate the public on the basics of earthquake activity. This is why the multimedia approach to the project is essential. The more knowledge that is gained by scientists and general public alike, the better our responses to earthquakes will be.

'Campbell, L.R., Menegon, L., 2019. Transient high strain rate during localised viscous creep in the dry lower continental crust (Lofoten, Norway). Journal of Geophysical Research - Solid Earth, 124. https://doi.org/10.1029/2019/Bo18052.

\section{Project Insights}

FUNDING

This project was supported by funding from the Natural Environment Research Council.

\section{CONTACT DETAILS \\ Dr Luca Menegon \\ Principal Investigator}

T: +441752584931

E: luca.menegon@plymouth.ac.uk

W: http://gtr.rcuk.ac.uk:80/

projects?ref=NE/Poo1548/1

\section{BIOS}

Dr Luca Menegon is Associate Professor of Geology at the University of Oslo, where he investigates lower crustal earthquakes. He has previously worked at the University of Plymouth, where he led the Centre for Research in Earth Sciences. His research interests include the brittle deformation and the viscous flow of rocks in the Earth's interior and the dynamics of the deepest portions of earthquake-generating faults.

Professor lain Stewart is Professor of Geoscience Communication at the University of Plymouth, UK, and serves as Director of its Sustainable Earth Institute. In 2018, he gained recognition as the UNESCO Chair in Geoscience and Society. Stewart's academic roots are in active tectonics and geohazards. After completing a BSc in Geography and Geology at Strathclyde University and a PhD in Earthquake Geology at the University of Bristol, he taught Earth Sciences at Brunel University until 2002. In 2004, he joined the University of Plymouth, where he developed his interdisciplinary interests in geo-communication.

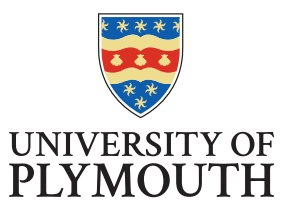

NERC SCENCE OETHE 